Jurnal Teknologi; bil. 25, Disember 1996 hlm. 37-43

(C)Universiti Teknologi Malaysia

\title{
PENYELESAIAN KAMIRAN NYATA \\ YANG TEPAT BAGI PERSAMAAN RESAPAN LINEAR TERITLAK BERPOTENSI AFIN
}

\author{
ZAINAL ABDUL AZIZ \\ Jabatan Matematik \\ Universiti Teknologi Malaysia \\ Karung Berkunci 791, 80990 Johor Bahru, Johor \\ SHAHARIR MOHAMAD \\ Jabatan Matematik \\ Universiti Kebangsaan Malaysia \\ 43600 UKM Bangi, Selangor
}

\begin{abstract}
Abstrak. Penyelesaian tepat berkamiran nyata, bagi persamaan resapan linear teritlak berpotensi afin, diperoleh dalam bentuk yang serupa dengan penyelesaian kamiran (Feynman) fungsian yang sedia ada.

Abstract. For the generalised linear diffusion equation with an affine potential, we obtain the exact real integral solution in a form similar to the existing functional (Feynman) integral solution.
\end{abstract}

\subsection{PENGENALAN}

Kewujudan penyelesaian kamiran lintasan bagi persamaan resapan linear teritlak dalam matra satu berbentuk:

$$
\psi_{t}(x, t)=\alpha \psi_{x x}(x, t)-\beta V(x, t) \psi(x, t), \psi(x, 0)=\phi(x)
$$

dengan $\alpha, \beta$ adalah pemalar kompleks yang sesuai (pilihan tertentu $\alpha$ dan $\beta$ memberikan sama persamaan haba atau Schrödinger) dan subskrip menandakan terbitan separa, telah dipostulat lama dahulu oleh Feynman [2] bagi kasus $\alpha=i h / 2 m$ dan $\beta=i / h$ (iaitu persamaan Schrödinger bagi zarah berjisim $m ; 2 \pi h=h$ pemalar Planck). Kini penyelesaian kamiran lintasan itu terkenal sebagai 'kamiran Feynman':

$$
\psi(x, t)=\int \operatorname{eksp}\left\{(i / h) \int_{0}^{t}\left[(m / 2) \dot{\gamma}^{2}(s)-V(\gamma(s))\right] d s\right\} \cdot \phi(\gamma(0)) d \gamma,
$$

pada 'kamiran' dilakukan ke atas semua lintasan klasik $\gamma(\mathrm{s})$ yang memenuhi $m \ddot{=}-(\partial V / \partial \gamma)$, $\gamma(0)=y, \gamma(t)=x$ titik menandakan terbitan terhadap $s$. Walau bagaimanapun, sehingga kini 'kamiran Feynman' itu masih memiliki kecacatan radikal di segi justifikasi matematiknya (Roesptorf [7]), khususnya berkaitan 'sukatan kompleks'nya. Semenjak Feynman [2] ramai penyelidik cuba memformulasi berbagai-bagai pendekatan rapi bagi memaktubkan kewujudan kamiran tersebut, walaupun umum mempersetujui bahawa formulasi-formulasi tersebut masih tersisih daripada hipotesis Feynman itu (Shaharir [11] untuk perbincangan lanjut). Walau bagaimanapun, bagi kasus $\alpha>0$ dan $\beta>0$ (persamaan haba atau resapan 
klasik), bentuk penyelesaian kamiran fungsian persamaan (1) terkenal semenjak analisis rapi Kac [3] lagi sebagai (dinamai juga rumus Feynman-Kac atau kamiran 'Wiener'):

$$
\left.\psi(x, t)=\int \operatorname{eksp}\left[-\beta \int_{0}^{t} V(\psi(s)) d s\right] \rho(\gamma(0))\right) d W \gamma,
$$

kamiran dilakukan ke atas set fungsi selanjar dalam selang $[0, \mathrm{t}]$ dengan $\gamma(t)=0$ dan $d W(\gamma)$ ialah sukatan Wiener; atau sebagai jangkaan kebarangkalian

$$
\psi(x, t)=J_{W}\left(\operatorname{eksp}\left[-\beta \int_{0}^{t} V(\gamma(s)) d s\right] \phi(\gamma(0))\right) .
$$

Sesungguhnya keputusan (4) itu merangsang kepercayaan beberapa pihak, terutamanya yang ingin menghayati 'kamiran Feynman' seperti yang diutarakan oleh Shaharir [9] bahawa, sekurang-kurangnya untuk beberapa potensi $V$ yang penting dan dengan $\alpha, \beta$ yang sesuai, wujud penyelesaian tepat bagi (1) dalam bentuk kamiran nyata

$$
\psi(x, t)=J_{M}\left[\operatorname{eksp}\left\{\beta \int_{0}^{t} V(\gamma(s)) d s\right\} \mathbb{E}(t, x, .) \quad \phi(\gamma(0))\right]
$$

untuk suatu $\mathbb{E}$ yang boleh ditentukan, dengan syarat lintasan klasik $m \ddot{\gamma}=\frac{\partial V}{\partial \gamma}, \gamma(t)=$ $x, \gamma(0)=y$. Konjektur (5) ialah jangkaan terhadap suatu taburan $M$ seperti taburan normal kompleks $N\left(x, \sigma^{2}(t)\right)$ dengan $\min x$ dan varians $\sigma^{2}(t)$ (Shaharir [10]).

Shaharir dan Hafsah [13] (lihat rujukan terkandung bagi kerja terdahulu dalam arah ini) mendakwa memperoleh penyelesaian persamaan resapan teritlak (1) bagi kasus potensi $V=0$, dalam bentuk penyelesaian tepat berkamiran nyata menerusi penjelmaan Fourier. Namun demikian, Shaharir dan Zainal [14] mendapati keputusan mereka itu sebenarnya sah bagi potensi pemalar sahaja. Sesungguhnya kasus ini agak remeh. Justeru itu, makalah ini memberikan satu lagi cara untuk melihat kewujudan suatu penyelesaian tepat berkamiran nyata, yang menyerupai (5), bagi persamaan satu (1) dengan potensi afin $V=L x+P$ dalam matra satu (Shaharir [12], Shaharir dan Zainal [15]), bagi pendekatan lebih umum). Motivasi kepada pendekatan ini terbit daripada isu pengungkapan penyelesaian resapan bagi $V=L x$ ke dalam bentuk kamiran Feynman yang diingini seperti konjektur (5). Masalah penyelesaian persamaan Schrödinger berpotensi linear ini sudah terkenal boleh diselesaikan menerusi kaedah pemisahan pemboleh ubah yang memberikan penyelesaian pemboleh ubah yang memberikan penyelesaian (Landau \& Lifshitz [4])

$$
\begin{aligned}
& \psi(x, t)=\int_{-\infty}^{\infty} \mathbb{A}(\lambda) \operatorname{eksp}(-i \lambda t) \mathbb{E}(\xi) \quad d \lambda \\
& \xi=\left(x-\frac{h \lambda}{L}\right) \cdot\left(\frac{-\beta L}{\alpha}\right)^{1 / 3}, \alpha=\frac{i h}{2 m} ; \beta=i / h
\end{aligned}
$$

atau

$$
\psi(x, t)=\int_{-\infty}^{\infty} \int_{-\infty}^{\infty} \phi(y) \operatorname{eksp}(-i \lambda t) \mathbb{X}(\eta) \quad \mathbb{X}(\xi) \quad d \lambda \quad d y
$$

dengan

$$
\mathbb{X}(\xi)=\frac{1}{2 \pi} \int_{-\infty}^{\infty} \operatorname{eksp} i\left[\left(u^{3} / 3\right)+\xi u\right] d u
$$


ialah fungsi Airy, $\eta=\left(y-\frac{h \lambda}{L}\right) \cdot\left(\frac{-\beta L}{\alpha}\right)^{1 / 3}$.

Namun penyelesaian (6) yang terhasil itu tidaklah sedia atau mudah terungkap sebagai 'kamiran Feynman' yang diingini itu.

Sebagaimana yang telah dimaklumi oleh ramai penyelidik, kaedah kamiran lintasan Feynman kini menjadi kaedah perkasa dalam pelbagai bidang fizik daripada teori medan terkuantum sehinggalah fizik jirim terpeluwap dan fizik kimia (polimer) (lihat Lundqvist et. al [16]). Matlamat utama kajian kami yang giat diusahakan kini ialah untuk memberikan justifikasi matematik yang kukuh kepada 'kamiran Feynman' itu. Usulan berikutnya merupakan keputusan utama makalah ini.

\subsection{KEPUTUSAN}

Usulan:

Persamaan resapan linear teritlak bagi potensi afin $V(z)=L z+P, L$ dan $P$ kompleks, dalam matra satu seperti pada persamaan (1), berpenyelesaian kamiran nyata yang tepat

$$
\begin{aligned}
& \psi(x, t)=\frac{1}{\sigma(t) \sqrt{2} \pi} \int_{-\infty}^{\infty}\left\{\operatorname{eksp} \frac{\left(-(x-y+\mu(t))^{2}\right)}{2 \sigma^{2}(t)}\right. \\
& \left.\operatorname{eksp}\left[-\beta\left(\int_{0}^{t} V(\gamma(s)) d s+\mathbb{E}(t)\right)\right] \phi(y)\right\} d y, \quad t>0
\end{aligned}
$$

Jika $\alpha, \beta$ nombor kompleks yang memenuhi sifat $N y(\alpha) \geqslant 0$; dengan $\phi € S_{c}$ ruang Schwartz, $\sigma^{2}(t)=2 \alpha t, \mu(t)=0, \mathbb{E}(t)=-\left(\frac{L^{2} t^{3}+\alpha \beta^{2} L^{2} t^{3}}{12}\right)$ dan $\gamma(s)$ lintasan klasik zarah berjisim niskala $m=(-1 / 2 \alpha \beta)$ yang memenuhi $m \ddot{\alpha}=-(\partial V(\gamma(s)) / \partial \gamma)$, dengan syarat $\gamma(t)=x$ dan $\gamma(0)=y$.

\section{Bukti:}

Keputusan $V=0$ (Shaharir [8]) dan konjektur (5) mengesyorkan penyelesaian tepat berkamiran nyata itu berbentuk $\psi(x, t)=\int_{-\infty}^{\infty} G(x, t ; y, O) \phi(y) d y, t>0$, fungsi Green bagi (1),

$$
\begin{gathered}
=\frac{1}{\sigma(t) \sqrt{ } 2 \pi} \int_{-\infty}^{\infty}\left\{\operatorname{eksp} \frac{\left(-(x-y+\mu(t))^{2}\right)}{2 \sigma^{2}(t)}\right. \\
\left.\operatorname{eksp}\left[-\beta\left(\int_{0}^{t} V(\gamma(s)) d s+\mathbb{E}(y, t)\right)\right] \phi(y)\right\} d y, \quad t>0
\end{gathered}
$$

atau

$$
=\int_{-\infty}^{\infty} \mathbb{F}(x, y, t) \operatorname{eksp}\left[-\beta\left(\int_{0}^{t} V(\gamma(s)) d s+\mathbb{E}(y, t)\right)\right] \phi(y) d y,
$$

dengan

$$
\mathbb{F}(x, y, t)=\frac{1}{\sigma(t) \sqrt{ } 2 \pi} \operatorname{eksp}\left(-\frac{\left.(x-y+\mu(t))^{2}\right)}{2 \sigma^{2}(t)}\right),
$$

dan $\sigma(t), \mu(t), \mathbb{E}(y, t)$ masih belum diketahui.

Boleh diperhatikan bahawa (8(a)) mengimplikasikan 


$$
\begin{gathered}
\psi_{t}=\int_{-\infty}^{\infty}\left\{\left[\mathbb{F}_{t}-\beta \mathbb{F}\left\{\int_{0}^{t} \partial_{t} V(\gamma(s)) d s+V(x)+\mathbb{E}_{t}(y, t)\right\}\right]\right. \\
\left.\operatorname{exsp}\left[-\beta\left(\int_{0}^{t} V(\gamma(s)) d s+\mathbb{E}(y, t)\right)\right] \phi(y)\right\} d y
\end{gathered}
$$

$\forall(x, t), t>0 ;$ dan

$$
\begin{gathered}
\alpha \psi_{x x}-\beta V(x) \psi=\int_{-\infty}^{\infty}\left\{\left[\alpha \mathbb{F}_{x x}-2 \alpha \beta \mathbb{F}_{x} \int_{0}^{t} \partial_{x} V(\gamma(s)) d s+\left[\alpha\left(\beta \int_{0}^{t} \partial_{x} V(\gamma(s)) d s\right)^{2}-\right.\right.\right. \\
\left.\left.\beta V(x)] \mathbb{F}] \operatorname{eksp}\left[-\beta\left(\int_{0}^{t} V(\gamma(s)) d s+\mathbb{E}(y, t)\right]\right)\right] \phi(y)\right\} d y, \forall(x, t), t>0 .
\end{gathered}
$$

Menerusi (9(a), (b)), persamaan (8(b)) bagi kasus potensi $V$ afin memenuhi (1) jika

$$
\begin{gathered}
\mathbb{F}_{t}-\beta \mathbb{F}\left\{\int_{0}^{t} \partial_{t} V(\gamma(s)) d s+V(x)+\mathbb{E}_{t}(y, t)\right\}= \\
\alpha \mathbb{F}_{x x}-2 \alpha \beta \mathbb{F}_{x} \int_{0}^{t} \partial_{x} V(\gamma(s)) d s+\left[\alpha\left(\beta \int_{0}^{t} \partial_{x} V(\gamma(s)) d s\right)^{2}-\beta V(x)\right] \mathbb{F} .
\end{gathered}
$$

Menerusi (8(c)), persamaan (10(a)) boleh ditulis semula sebagai

$$
\begin{gathered}
\left\{-\frac{\sigma_{t}}{\sigma}-\frac{x-y+\mu}{\sigma^{2}} \mu_{t}+\frac{(x-y+\mu)^{2}}{\sigma^{3}} \sigma_{t}\right\}=\left\{\alpha\left[-\frac{1}{\sigma^{2}}+\frac{(x-y+\mu)^{2}}{\sigma^{4}}\right]+\right. \\
\beta\left\{\int_{0}^{t} \partial_{t}(\gamma(s)) d s+\mathbb{E}_{t}(y, t)\right\}+2 \alpha \beta \frac{(x-y+\mu)}{\sigma^{2}} \int_{0}^{t} \partial_{x} V(\gamma(s)) d s+ \\
\left.\alpha\left(\beta \int_{0}^{t} \partial_{x} V(\gamma(s)) d s\right)^{2}\right\} .
\end{gathered}
$$

Boleh diperlihatkan bahawa persamaan $m \ddot{\gamma}=-(\partial V(\gamma(s) / \partial \gamma)$, dengan syarat $\gamma(t)=x$ dan $\gamma(0)=y$ memberikan lintasan klasik zarah berjisim $m$ :

$$
\gamma(s)=(-L / 2 m)\left(s^{2}-t^{2}\right)+\ell(s-t)+x, \quad \ell=(1 / t)\left[x-y+\left(L t^{2} / 2 m\right)\right] .
$$

Dengan mengambil perhatian bahawa sebutan-sebutan lain berkuasa $y$ kurang daripada 3 maka kita boleh anggap

$$
\mathbb{E}(y, t)=A(t)+B(t) y+C(t) y^{2} .
$$

Seterusnya penyamaan pekali $x^{n} y^{m}$ dalam hubungan (10(b) memberikan $\sigma^{2} \alpha(t), \mu=$ $0, A(t)=-\left(L^{2} t^{3} / 12 m\right),-\left(\alpha \beta L^{2} t^{3} / 12\right), B=O \operatorname{dan} C=O$.

Keputusan ini mengimplikasikan bentuk fungsi Green 


$$
\begin{gathered}
\left.G(x, t ; y, 0)=\frac{1}{\sqrt{ } 4 \pi \alpha t} \operatorname{eksp} \frac{\left(-(x-y)^{2}\right)}{4 \alpha t}\right) \operatorname{eksp}\left(-\beta \int_{0}^{t} V(\gamma(s)) d s+\left(\beta L^{2} t^{3} / 12 m\right)+\right. \\
\left.\left(\alpha \beta^{2} L^{2} t^{3} / 12\right)\right) \\
=\frac{1}{\sqrt{ } \pi \alpha t} \operatorname{eksp}\left[\frac{\left(-(x-y)^{2}\right)}{4 \alpha t}-\frac{1}{2} L \beta t(x+y)+\frac{L^{2} \beta^{2} \alpha t}{12}-\beta P t^{3}\right]
\end{gathered}
$$

Boleh diperlihatkan bahawa $G(x, t ; y, O)$ berbentuk (11(a)) memenuhi persamaan $G_{t}=$ $\alpha G_{x x}-\beta V G$ (sebagai suatu fungsi Green) apabila syarat $m=-1 / 2 \alpha \beta$ dipenuhi.

Seterusnya kami tunjukkan bahawa $G(x, t ; y, O)$ di atas sememangnya sah menjadi fungsi Green untuk $\alpha, \beta$ nombor kompleks yang sesuai, dengan memperlihatkan keesahan $\operatorname{had}_{t \rightarrow 0} G(x, t ; y, O)=\delta(x-y)$. Khususnya, diselidiki (11(b)) bagi $\alpha, \beta$ nombor kompleks supaya memenuhi (Lightill [5])

$$
\operatorname{had}_{t \rightarrow 0} \int_{-\infty}^{\infty} G(x, t ; y, 0) \phi(x) d x=\phi(y), \quad \phi \in \mathcal{S}_{c} .
$$

Untuk sebarang $\phi \in \mathcal{S}_{c}$ dant $>0$, didapati

$$
\begin{gathered}
\left|\int_{-\infty}^{\infty} \frac{1}{\sqrt{ } 4 \pi \alpha t} \operatorname{eksp}\left[\frac{-\left(x-y+\alpha \beta L t^{2}\right)^{2}}{4 \alpha t}\right] \phi(x) d x-\phi(y, t)\right| \\
=\mid \int_{-\infty}^{\infty} \frac{1}{\sqrt{ } 4 \pi \alpha t} \operatorname{eksp} \frac{\left(-w^{2}\right)}{4 \alpha t}\left\{\left(\phi\left(\omega+y-\alpha \beta L t^{2}\right)-\phi\left(y-\alpha \beta L t^{2}\right)\right\} d \omega \mid,\right.
\end{gathered}
$$

$\omega=x-y+\alpha \beta L t^{2}$, dengan syarat $N y(\alpha) \geq 0$ supaya

$\int_{-\infty}^{\infty} \frac{1}{\sqrt{4 \pi \alpha t}} \operatorname{eksp} \frac{\left(-\omega^{2}\right)}{4 \alpha t} d \omega=1$ (lihat Carrier et al. [1], Shahrir [10]),

$$
\begin{aligned}
& \leq \text { maks. }|\phi \prime(\omega)| \int_{-\infty}^{\infty} \frac{1}{4 \pi \alpha t} \operatorname{eksp} \frac{\left(-\omega^{2}\right)}{4 \alpha t}|\omega| d \omega, \\
= & (4 \alpha t / \pi)^{1 / 2} \text { maks. }\left|\phi^{\prime}(\omega)\right| \longrightarrow 0 \text { apabila } t \longrightarrow 0 .
\end{aligned}
$$

Ini bermakna $\operatorname{had}_{t \rightarrow 0} G(x, t ; y, O)=\delta(x-y)$. Ini melengkapkan pembuktian. Usulan dengan bentuk (8(a)) dikenal pasti

\section{Ulasan:}

(a) Keputusan di atas boleh juga dibuktikan dengan menyelesaikan secara terus persamaan (1) menerusi teknik penjelmaan Fourier, seperti yang terlaksana dalam Shaharir dan Zainal [14]. Bentuk penyelesaian kamiran nyata (7) itu didapati mempunyai beberapa versi lain, (Shaharir [12], Shaharir dan Zainal [15,16]) dan sila rujuk kerja-kerja kami ini bagi ulasan yang relevan lagi terperinci berkaitan keputusan di atas. Khususnya mengenai kasus penting $\alpha>O, \beta>0$ bagi resapan klasik dan $\alpha=i h / 2 m$ dan $\beta=i / h$ (khayal tulen) bagi persamaan Schrödinger yang sedia terangkum dalam model resapan teritlak (1) itu dan bagaimana 'sikatan Feynman' dan sekaligus 'kamiran Feynman' dapat dibina.

(b) Bagi kasus potensi pengayun harmonik, kami masih mendapati bahawa pendekatan makalah ini menghasilkan keputusan yang agak berserabut. Perspektif kami dalam Shaharir dan Zainal $[15,16]$ lebih menyakinkan dalam konteks ini. 


\subsection{KESIMPULAN}

Makalah ini mengesahkan kewujudan penyelesaian tepat berkamiran nyata (7) bagi persamaan resapan teritlak (1) berpotensi afin dengan $\alpha$ dan $\beta$ nombor kompleks; $\alpha \beta$ bukan sifar dan $N y(\alpha) \geq 0$. Keputusan ini menunjukkan adanya penyelesaian kamiran nyata yang menyerupai konsep kamiran lintasan Feynman (2), sama ada bagi persamaan Schrödinger ( $\alpha, \beta$ khayalan tulen) mahupun resapan klasik $(\alpha>0, \beta>0)$ dengan potensi afin yang selama ini dilihat penyelesaiannya sebagai kamiran fungsian atas set fungsi selanjar sahaja (contohnya kamiran Weiner (3)) dan bukan atas set lintasan klasik. Seterusnya keputusan ini boleh diungkap secara formal sebagai

$$
\psi(x, t)=J_{N\left(x, \sigma^{2}\right)}\left[\operatorname{eksp}\left(-\beta \int_{0}^{t} V(\gamma(s)) d s\right) . \mathbb{E}(t) \phi(\gamma(0))\right]
$$

jangkaan terhadap suatu taburan normal kompleks $N\left(x, \sigma^{2}(t)\right)$ dengan min $x$ dan varians $\sigma^{2}(t)=2 \alpha t$, yang menyerupai konjektur (5) dengan $\mathbb{E}(t)=\left(\frac{\beta L^{2} t^{3}+\alpha \beta^{2} L^{2} t^{3}}{12}\right)$.

Penyelesaian (12) itu jelas membayangkan adanya proses stokastik yang melandasi resapan teritlak (1) berpotensi afin itu, walaupun kami belum dapat mengecam secara terperinci bentuk proses stokasik tersebut (Shaharir dan Zainal [15],[16] bagi perbincangan dan matlamat kami mengikut arah ini, khususnya hasrat kami untuk menjelmakan hasil (12) dalam ruang nyata kepada ruang fungsi supaya dapat dimaktubkan 'sukatan Feynman' dan sekaligus 'kamiran Feynman'). Walau apapun hasil (12) itu adalah realisasi penyelesaian berbentuk kairan Feynman yang tepat dalam sebutan kamiran nyata (iaitu bukan kamiran fungsian) bagi persamaan (1) berpotensi afin. Tambahan pula, keputusan di atas memaparkan juga suatu pendekatan baru secara matematik kepada penyatuan di antara domain klasik (persamaan resapan klasik) dan domain kuantum (persamaan Schrödinger) menerusi persamaan resapan teritlak (1) berpotensi afin.

\subsection{PENGHARGAAN}

Pengarang kedua (Z. b. A. A) berterima kasih kepada Universiti Teknologi Malaysia, Skudai di atas pembiayaan pengajian kedoktoran beliau di Universiti Kebangsaan Malaysia, Bangi.

\section{RUJUKAN}

[1] G. F. Carrier, M. Krook and C. E. Pearson, Functions of a Complex Variable ((1966)), Mcgraw Hill Co.,, New York.

[2] R. P. Feynman, Space-time approach to non-relativistic quantum mechanics, Rev. Mod. Phys. .20 ((1948)), 367-387.

[3] M.Kac, Probality and Related Topics Sciences ((1959)), Interscince Pub., Reading.

[4] L. D. Landau and E. M. Lifshitz, Quantum mechanics (non-relavistic theory) Third Edition (1977), Pergamon Press.

[5] M. J. Lighthill, Introduction to Fourier Analysis and Generalised Funtions (1964), Cambridge Univ. Press, Cambridge.

[6] S. Lundqvist, A. Ranfagni, V. Sa-yakanit and L. S. Schulman (pyt.), Path Summation: Achievements and Goals (1988), World Scientific, Singapore.

[7] G. Roepstorf, Path Intergral Approach to Quantum Pysics: An Introduction (1994), Springer-Verlag, Berlin.

[8] Shaharir b. M. Z., Teori Penjelmaan Fourier dan Kegunaannya (1986), Dewan Bahasa \& Pustaka, Kuala Lumpur.

[9] Shaharir b. M. Z., New Framework for the Feynman intergral, Int. Jour. TheOr.Phys. 10 (1986), 1075-1094.

[10] Shaharir b. M. Z., On complex normal distribution 16 (1986), Sains Malaysiana, 397-408.

[11] Shahahrir b. M. Z., Satu sorotan tentang penyelesaian anlisis persamaan resapan 4 (1988), Matematika (U.T.M), 1-31. 
[12] Shaharir b. M. Z., Penyatuan proses resapan klasik dengan persamaan Schrödinger bagi potensi afin (1995), J. Fiz. Mal, 16, 1-14.

[13] Shaharir M. Z. and Hafsah A. M., Beberapa ulasan baru berkenaan dengan penyelesaian persamaan haba 16 (1987), Sains Malaysiana (Kuantitatif), 1-7.

[14] Shaharir M. Z. and Zainal A. A., On the axact real intergral solution of the generalised linear diffusion equation (1995), Sing. J. Phys, 11, 81-91.

[15] Shaharir M. Z. and Zainal A. A., Penyelesaian kamiran nyata berbentuk kamiran Feynman bagi persamaan resapan teritlak berpotensi linear, Prosiding Seminar Siswazah FSMK II, UKM.

[16] Shaharir M. Z. and Zainal A. A., Real intergral solution in term of classical path for the diffusion model with quadratic potential in one-dimensional Enclidean space (1995). 